\title{
III Concurso de Fotografia do Servidor Público
}

Descontração, de Eudemar Sousa de Moraes e A luz e o olhar, de Geminiano Cardoso dos Santos, foram as fotos premiadas (1. lugar preto $\mathrm{e}$ branco e 1 ? lugar cores) no III Concurso de Fotografia do Servidor Público, promovido pela Fundação Centro de Formação do Servidor Público - FUNCEP.

O Concurso é realizado anualmente sob a coordenação do Centro de Desenvolvimento da Administração Pública, com objetivo de incentivar e divulgar a arte da fotografia entre os servidores públicos. Este ano, 43 servidores participaram do evento, com um total de 192 fotos.

$\mathrm{Na}$ categoria preto e branco o 2 ? lugar ficou para Cidinha Coutinho, com o trabalho "Moldura". Duas outras fotos receberam Menção Honrosa: Futuro, Toninho Carvalho e Agricultor de Subsistência, José Antonio Marques.

Na categoria cores, o resultado foi o seguinte: 2. lugar para Serra Pela- da, de Sérgio Alves Ferreira, e Menção Honrosa para Água é Vida e Ballet da Natureza, ambas de Diógenes Borges Cardoso.

A comissão que escolheu os meIhores trabalhos do III Concurso de Fotografia foi composta por: Breyner Nobre Perdigão - Professor de Fo-. tografia; André Luiz Abrahão - Professor de Fotografia do CEUB; André Dusek - Ágil Foto Jornalismo; Luiza Helena da Silveira e Hermano Machado, representando a FUNCEP.

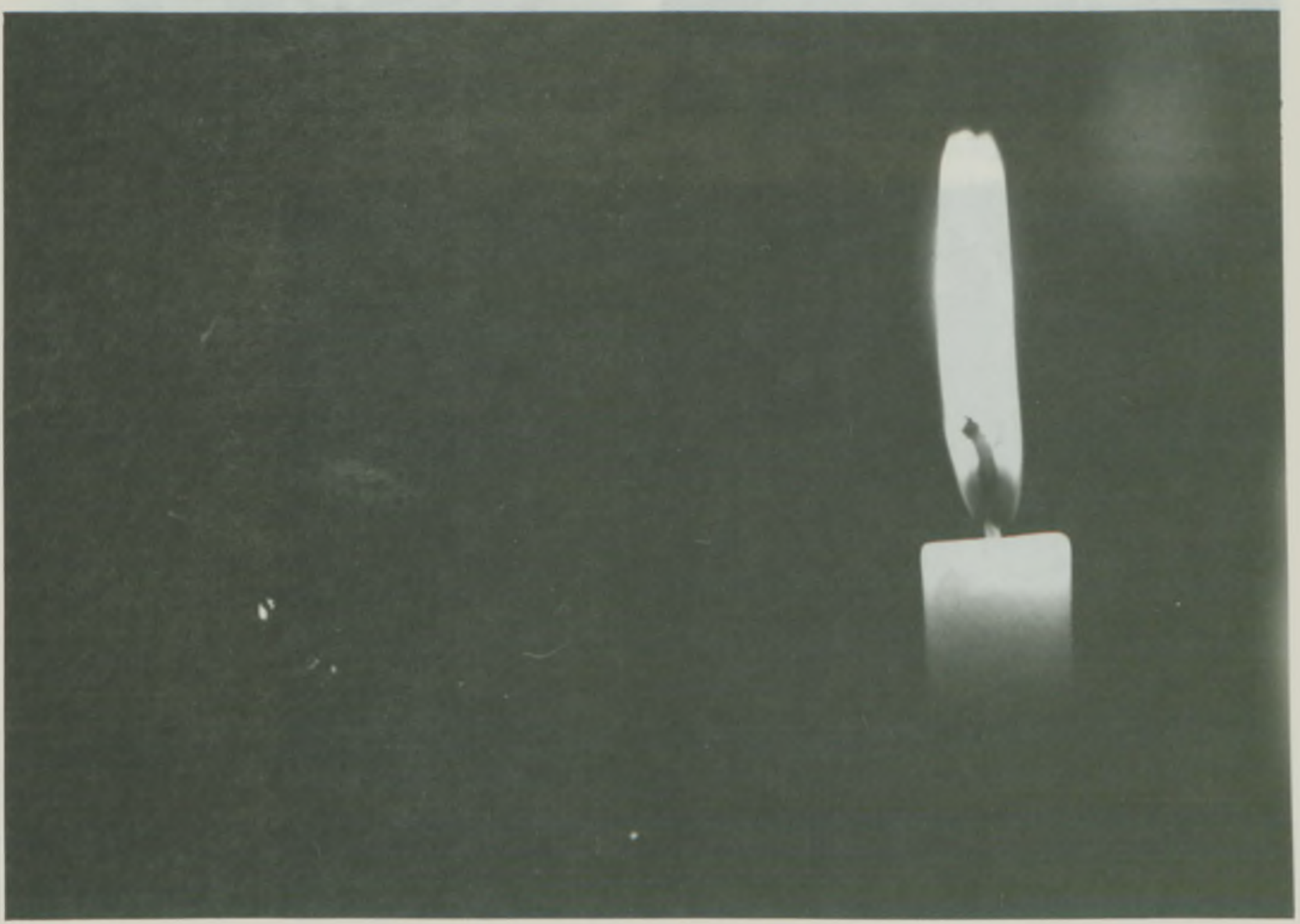

1. Lugar - Folo Colorida - Tírulo: A Luz e o Olhar - Forógrafo: Germiniano Cardoso dos Santos. 


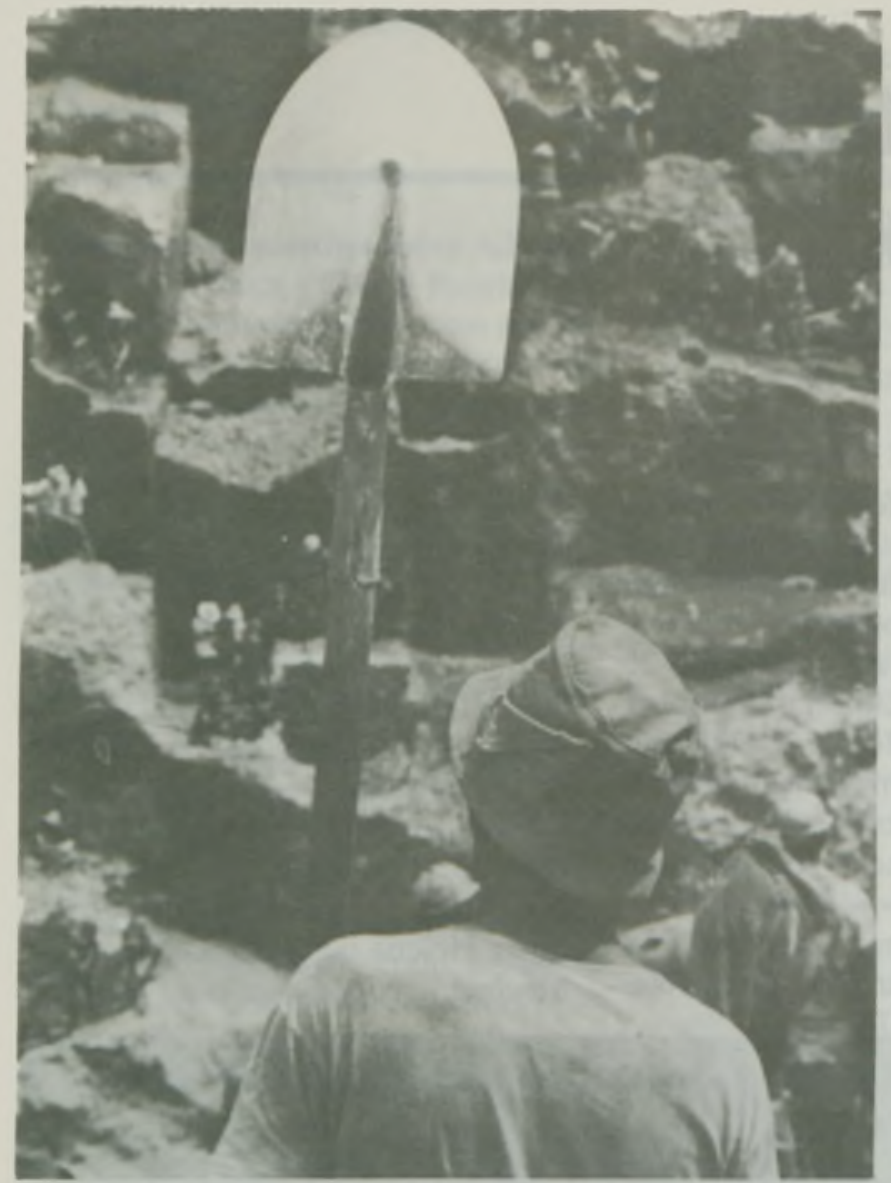

2. Lugar - Folo Colorida Tírulo: A Força do Garimpeiro Fotógrafo: Sérgio Alves Ferreira.

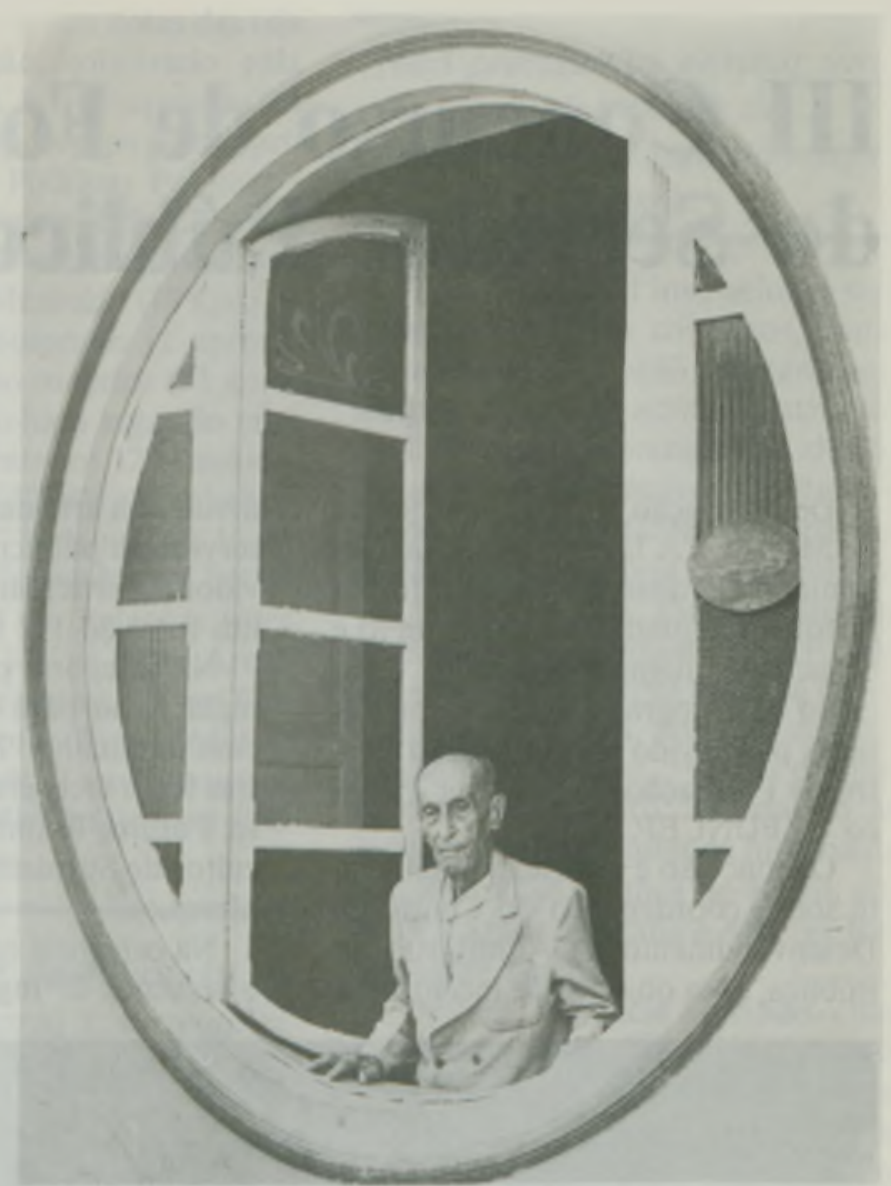

2. Lugar - Folo Prelo e Branco Tírulo: Moldura Fotografa: Cidinha Coutinho.

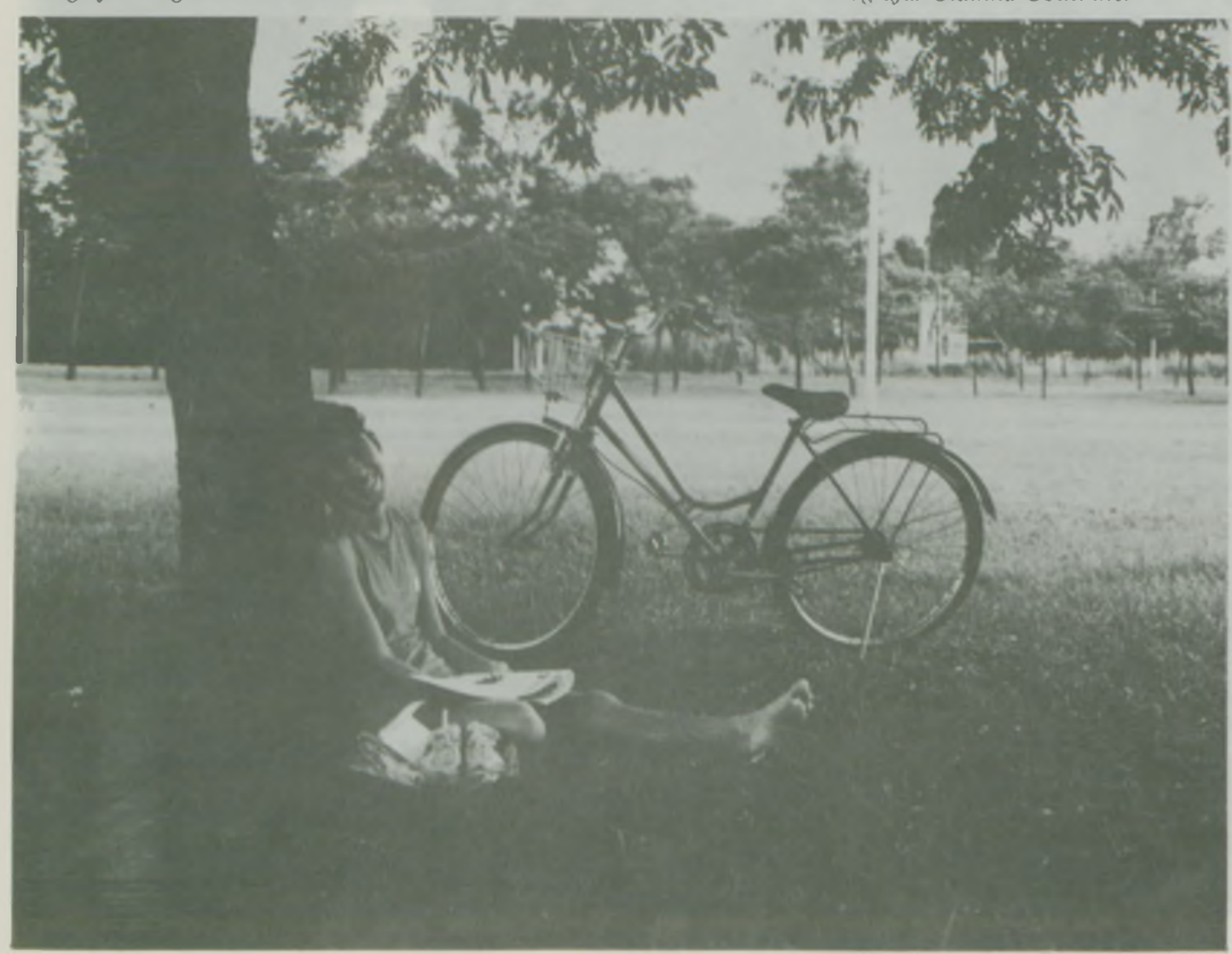

1. Lugar - Foto Preto e Branco

Tírulo: Descontração

Fotográfo: Eudemar Souza de Moraes. 




Mençào: Honrosa - Foto

Preto e Branco

Titulo: Futuro

Forógrafo: Toninho

Carvalho.






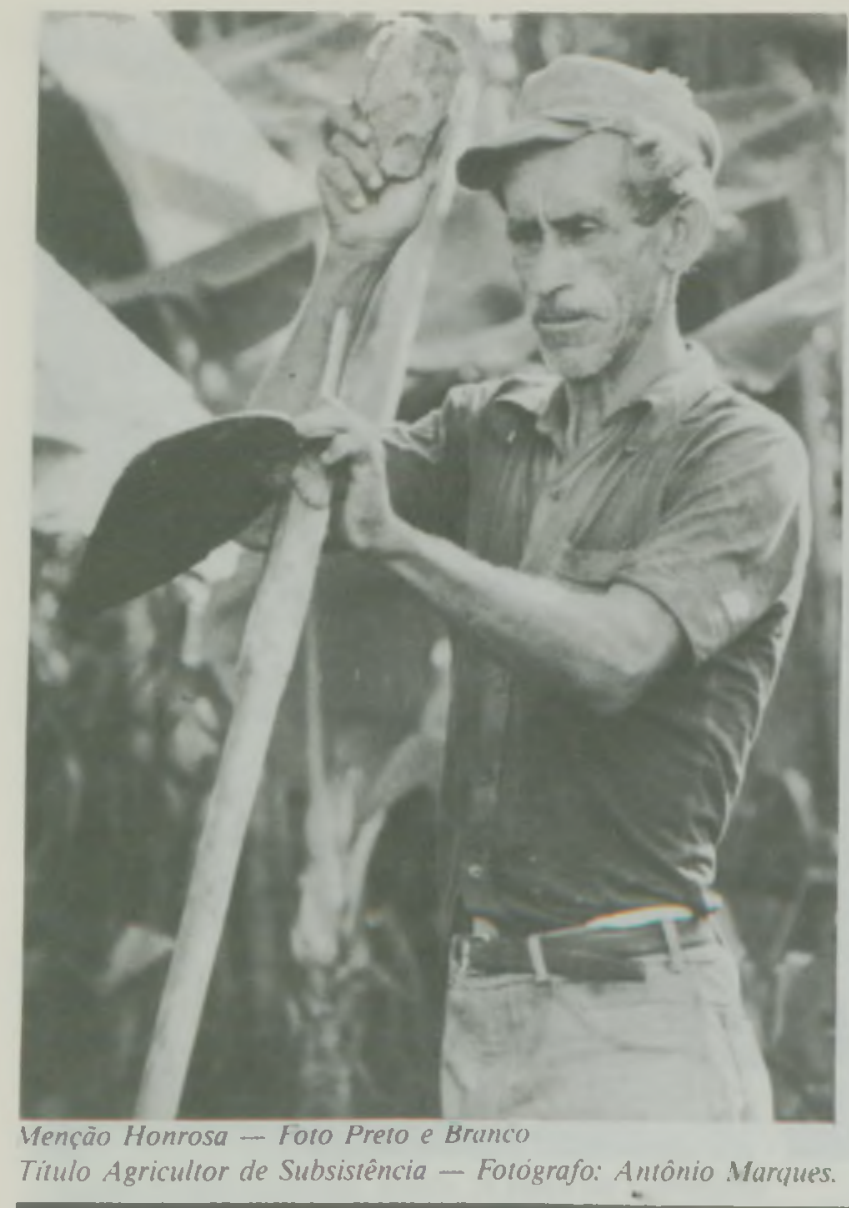

FUNCEP PUBLICAC̣ÕES

Um acervo de publicações sobre administraçào pública. Edições que não são encontradas com facilidade na linha oditorial de nossos livreiros.

\section{COLEC̣ÃO HISTÓRIA ADMINISTRATIVA DO BRASIL - HAB}

Projeto editorial de 40 volumes. De manoira sistomática, ob jetiva a cobertura integral da história da adminıstraçđo püblica bra sileira. Pesquisas e textos executados por ronumados professores e historiadores.

No momento, já foram editados 16 volumes, compreendendo os periodos Colonial e Imperial.

Minimo de 130 páginas; formato $22 \times 15,5 \mathrm{~cm}$; capa: 1 cor, papel chambril, $120 \mathrm{gr}$, plastificada; miolo: papel off set, $75 \mathrm{gr}$; todos com gráficos e tabelas.

\section{TITULO}

Administração Portuguesa no Bra sil - de Pombal a D. João

Brasil Sede da Monarquia. Brasil Reino - 1: parte

Brasil Sede da Monarquia. Brasil Reino - 2:" parte

Organização Política e Administrativa do Império

Organização e Administração do Ministério do Império

Organização e Administração do Ministério dos Estrangeiros

\section{CODIGO}

PRECTO

$\begin{array}{lll}206 & \text { Cz\$ } & 1.040,00 \\ 207 & \text { Cz\$ } & 970,00 \\ 208 & \text { Cz\$ } & 1.230,00 \\ 209 & \text { Cz\$ } & 1.520,00 \\ 210 & \text { Cz\$ } & 550,00 \\ 211 & \text { Cz\$ } & 580,00\end{array}$

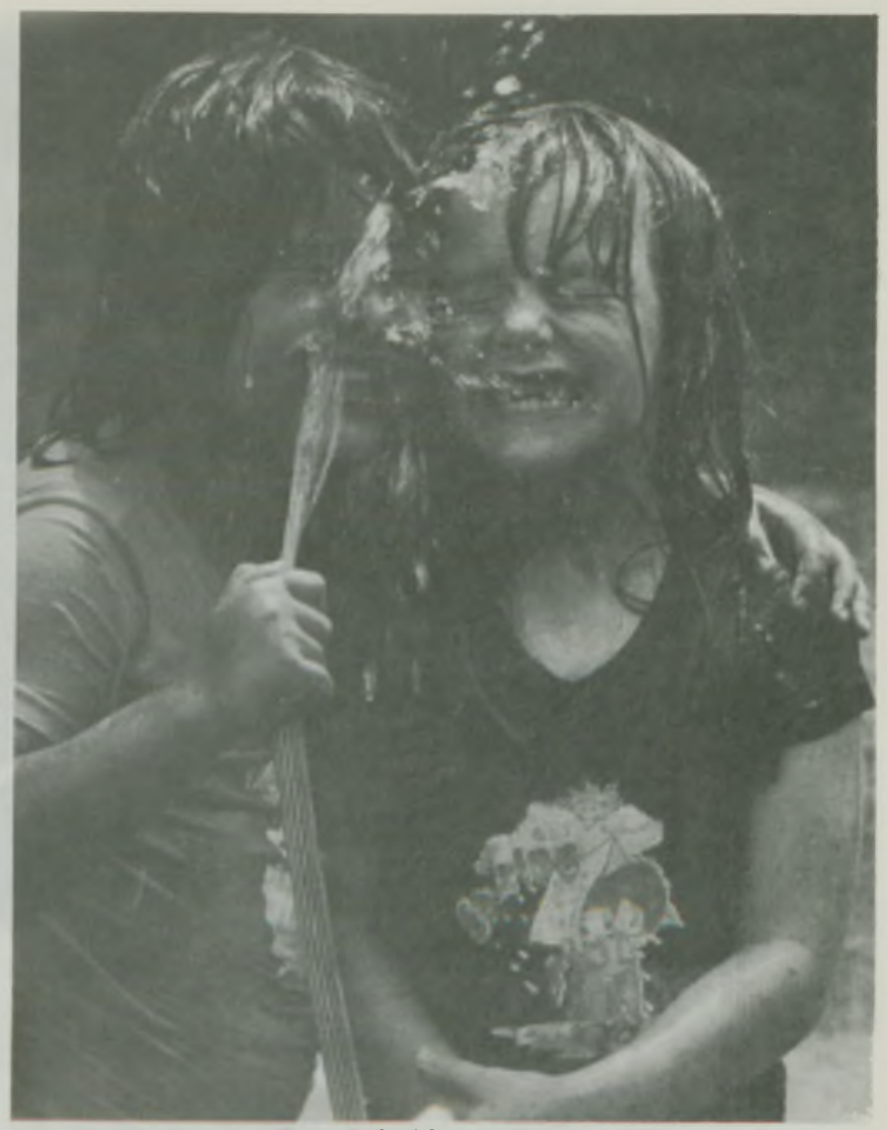

Mencdo Honrosa - Folo Colorida

Tíulo: Água é Vida - Fotógrafo: Diogenes Borges Cardoso.
CÓDIGO

PREC O

Organização e Administração do Ministério da Justiça no Império Organização e Administração do Ministério da Fazenda no Império Organização e Administração do Ministério da Agricultura no Império

Organização e Administração do Ministério da Marınha no Império

$\begin{array}{cr}212 & \text { Cz\$ } 1.330,00 \\ 213 & \text { Cz\$ } 1.170,00 \\ 214 & \text { Cz\$ } 1.470,00 \\ 215 & \text { Cz\$ } 1.920,00 \\ & \text { TOTAL Cz\$ } 11.780,00\end{array}$

(1)

